\title{
User perception of transfers in multimodal urban trips: A qualitative study
}

\author{
Rocio Cascajo (D), Elena Lopez, Fernando Herrero, and Andres Monzon \\ Universidad Politecnica de Madrid, TRANSyT, Madrid, Spain
}

\begin{abstract}
The aim of this article is to identify the factors affecting user perception of transfers in order to reduce the penalty associated with transfers. Policy makers can thus concentrate on the most relevant factors to achieve a more effective investment of public funds. We carried out an extensive review of the literature and identified a total of 45 factors. A qualitative study was then conducted in two Spanish cities, Vitoria and Madrid, consisting of various focus groups stratified by age. The results indicate that a combination of factors influence the perception of transfers. Time spent during transfers, both walking and waiting, is the main penalty associated with transfers. However, the provision of real-time passenger information helps reduce the perceived waiting time. Differences were found between cities and age groups. Two new factors were identified, mainly in Madrid: mental effort and activity disruption. We, therefore, advise policy makers to concentrate their efforts on providing real-time information to passengers, improving the frequency and reliability of services, and designing transfer areas to ensure continuity between transport modes and between information and communication systems.
\end{abstract}

\section{Introduction}

Transfers are an essential step in the trip chain, as they allow the public transport system to function as a multimodal network; thus, increasing the destinations available for passengers and improving the efficiency of the operation (JaraDíaz, Gschwender, \& Ortega, 2012; Liu, Pendyala, \& Polzin, 1997; Navarrete \& Ortúzar, 2013). However, transfers are perceived as one of the biggest burdens for transit users (Guo \& Wilson, 2011; Schakenbos, La Paix, Nijenstein, \& Geurs, 2016) as they basically represent a disruption in the user's transit trip, and entail a disutility or penalty (Bruun, 2007; Currie, 2005; Guo, 2003; Horowitz \& Zlosel, 1981; Liu et al., 1997; Navarrete \& Ortúzar, 2013; Wardman, 2001).

Research on transfer penalties is currently very active (De Keizer, Kouwenhoven, \& Hofker, 2015; Navarrete \& Ortúzar, 2013; Schakenbos et al., 2016). The concept of transfer penalty varies among authors. Following the approach by Currie (2005), who introduces a transfer penalty in the total generalized cost of a PT trip, and later by Iseki and Taylor (2009), three main components can be identified as part of the transfer penalty: a walking time penalty and its perception; a waiting time penalty and its perception; and a pure transfer penalty, independent of walking and waiting time, but dependent on other factors related to safety, comfort, climate, or personal conditions.

Some authors differentiate between the perceived disutility during these times (Bruun, 2007; Ceder, Chowdhury, Taghipouran, \& Olsen, 2013; Currie, 2005; Guo \& Wilson, 2011; Iseki \& Taylor, 2009; Liu et al., 1997; Navarrete \&
Ortúzar, 2013; Raveau, Guo, Muñoz, \& Wilson, 2014), while other researchers consider a transfer penalty as a whole, with no differentiation between waiting time and time spent in walking (Douglas \& Jones, 2013; Schakenbos et al., 2016). The pure transfer penalty, generically called "penalty" or "disruption", has only been addressed in some studies (Douglas \& Jones, 2013; Iseki \& Taylor, 2009; Wardman, 2001).

Transfers can be studied as part of the travel experience (Carreira, Patricio, Jorge, \& Magee, 2014; Carreira, Patricio, Jorge, Magee, \& Van Eikema Hommes, 2013; Friman, 2010), in which affective dimensions play a distinct role in the "transfer experience" (Friman, 2010; Jensen, 2012; Navarrete \& Ortúzar, 2013). Personal characteristics also influence the perception of factors related to transfers. This is the case of age (Broome, Worrall, Fleming, \& Boldy, 2013; Emmerson, Guo, Blythe, Namdeo, \& Edwards, 2013; Gwyther \& Holland, 2014; Hancock \& Rausch, 2010; Murray, 2015), which may imply a functional decline and influence the perception of barriers and facilitators to the "transfer experience".

Most studies use quantitative methods to identify the most important factors determining the transfer penalty (Ceder et al., 2013; Chowdhury \& Ceder, 2013a, 2013b, 2013c; Chowdhury, Ceder, \& Sachdeva, 2014; Douglas \& Jones, 2013; Liu et al., 1997). Recent research has increasingly featured qualitative approaches, particularly in transportation and travel behavior, to understand transportrelated conduct (see the review in Clifton \& Handy, 2003). Qualitative methods are a powerful tool for capturing transport users' perceptions, attitudes and emotions, and focus 
groups are frequently used as a technique (Ferrer, Ruiz, \& Mars, 2015, 2018; Hopkins \& Mandic, 2017; Kenyon \& Lyons, 2003). Focus groups (FG) have been used to explore topics such as the role of the built environment for short walking trips (Ferrer et al., 2015, 2018), the provision of integrated multimodal traveler information (Kenyon \& Lyons, 2003), issues related to motorcycle rider's safety (Huth, Füssl, \& Risser, 2014), the perception of cycling among high school students and their parents (Hopkins \& Mandic, 2017), or the perceived vulnerability in driving behavior (Gwyther \& Holland, 2014).

To our knowledge, no comprehensive studies have been carried out so far using solely focus groups to investigate the perception of transfers. This article, therefore, makes a novel contribution using a focus-group-based methodology to investigate transfer perceptions. A key element of our research is that FG were conducted in two cities with different public transport networks (Madrid and Vitoria, Spain) and with diverse age groups.

The article is organized as follows. After this introduction, Section 2 includes a review of the literature on the factors influencing transfer penalty and the methods used to investigate them. The focus group methodology applied in the study is outlined in Section 3, together with a description of how the FG were structured and conducted. Section 4 presents the study results and, finally, Section 5 sums up the main conclusions and offers policy recommendations to reduce the transfer penalty perceived by users.

\section{Literature review}

There is no consensus on the factors affecting the perception of transfers, nor on the methods used to identify them. It is therefore important to review the literature on these two key issues.

\subsection{Factors affecting transfer penalty}

This section presents the results of the literature review to identify the factors affecting the transfer penalty in multimodal trips. Table 1 shows the main factors identified, grouped according to themes and sub-themes, and the references in which these factors are mentioned, in chronological order. Some factors can be seen to be identified in many different studies (waiting and walking time in transfer, comfort, safety and security and information), suggesting that these recurrent factors may constitute the main components of user perception of transfers.

Some recent research (Iseki \& Smart, 2012) shows that socio-demographics and trip characteristics have an effect on PT user perception of transfers. Personal characteristics such as age, gender, and income have been found to be relevant in some studies (Chowdhury \& Ceder, 2013a, 2013b; Chowdhury et al., 2014; Raveau et al., 2014; Schakenbos, 2014; Wardman \& Hine, 2000). Health status and familiarity with the public transport system are also mentioned in Iseki and Taylor (2009). These factors depend completely on the individual and their beliefs and personal preferences, and some are related to the controllability experienced by the user. According to the Theory of Planned Behaviour (TPB), users manifest a stronger intention to take routes involving transfers when they have greater control over the situation (Chowdhury \& Ceder, 2013a). Health status is also important in determining both actual and perceived walking distance and time.

Trip characteristics such as frequency of PT use, trip purpose, modes of transport used, whether the user is carrying any luggage or is running late are all factors found in the literature reviewed. Of these, the frequency of PT use is the most cited factor. Some authors mentioned that frequent riders tend to be more familiar with the PT network and services and are therefore less likely to face uncertainties when transferring (Guo \& Wilson, 2007). The availability of information - either static information at connection points or real-time information at stations or via mobile phone applications - was also identified in the literature as a relevant factor affecting the transfer penalty (Atkins \& Polak, 1997; Hess, Brown, \& Shoup, 2004; Iseki \& Taylor, 2009; Navarrete \& Ortúzar, 2013; Smith \& Wheat, 2012). A satisfactory level of information reduces users' perceived time while increasing their perception of controllability. According to the TPB, the more control users feel they have over the situation, the greater their intention to use transfers (Chowdhury \& Ceder, 2013a, 2013c).

Time is the most recurrent theme in the literature, as it is one of the main deterrents for using routes with transfers. Transit riders are very sensitive to out-of-vehicle time involving walking and waiting. Of these, waiting time is most penalized by transit users within a transfer (Navarrete \& Ortúzar, 2013). Although actual waiting and walking times are easily and objectively measurable, the same cannot be said for their perception, which depends on many other factors (Bronzaft, Dobrow, \& O'Hanlon, 1976; Dziekan, 2008; Iseki \& Taylor, 2009; Lacy \& Bonsall, 2001; Reynolds \& Hixson, 1992; Woyciechowicz \& Shliselberg, 2005). For instance, there are some factors that do not depend on the individual but on factors beyond their control, such as service frequency, weather conditions, security and safety, all of which are identified in the literature as factors influencing the perception of waiting time (Dziekan, 2008; Dziekan \& Kottenhoff, 2007; Dziekan \& Vermeulen, 2006; Iseki \& Taylor, 2009). Inactivity while waiting for the next service also emerged as a relevant factor, and numerous works reported that waiting time is more penalized when it is unproductive (Dziekan \& Vermeulen, 2006; Iseki \& Taylor, 2009; Moreau, 1992). This may also explain the differences observed between the perception of waiting and walking time.

Among the factors relating to the built environment, comfort, safety and security and crowding were also mentioned in other studies. When estimating route choice models for metro networks, Raveau et al. (2014) considered different kinds of variables, including transfer experience characteristics, occupancy, and comfort indicators. Wardman and Hine (2000) reported that the value associated with transfer time depends on the safety and comfort of the surroundings. Other authors (Dziekan, 2008; Horowitz \& Thompson, 1995; 


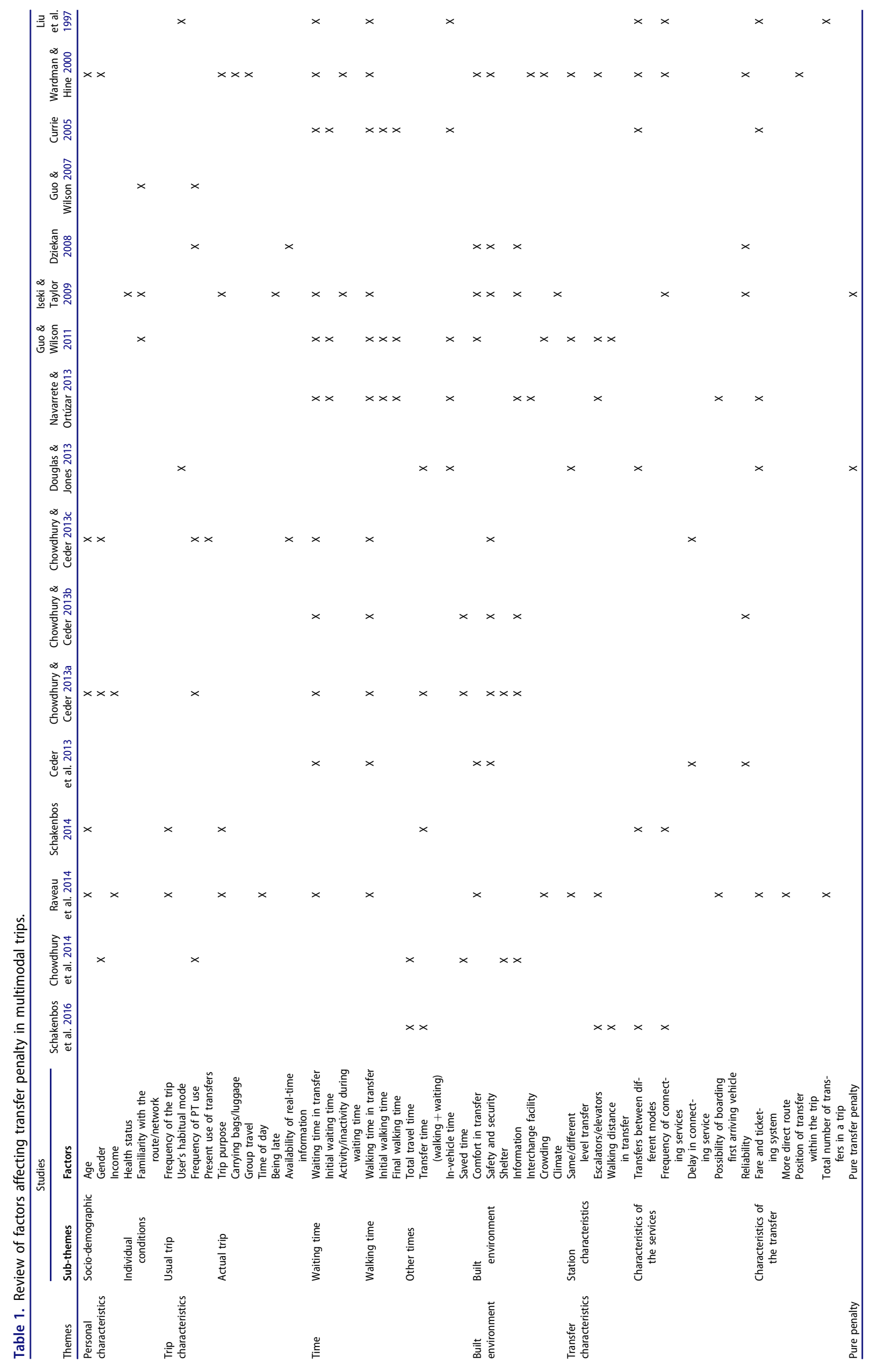


Iseki \& Taylor, 2009) have shown that safety and security in the facilities are factors affecting perceived waiting time. One finding was that crowding was seen as increasing the value of time spent moving or waiting in very crowded stations, doubling the "cost" of a minute compared to medium occupancy conditions (Douglas \& George, 2005). Other authors have also documented increased anxiety, stress and feelings of exhaustion, perceptions of risk to personal safety and security as impacts of crowding on passengers' health and wellbeing (Tirachini, Hensher, \& Rose, 2013).

A number of other factors affecting user perception of transfers concern the transfer characteristics, such as whether the transfer involves different levels - and the existence of escalators or lifts - and the modes of transport involved in the transfer. Some authors indicate that "same platform" transfers at rail stations had a lower penalty than "up/down" transfers requiring a change of platform via escalators, lifts, or stairs (Douglas \& Jones, 2013; Wardman \& Hine, 2000). Douglas and Jones (2013) also found that the penalty associated with a bus-rail transfer was nearly twice as high as a rail-rail transfer. The reliability of the service was also identified in the literature as a relevant factor for affecting transfer penalty (Atkins \& Polak, 1997; Ceder et al., 2013; Chowdhury \& Ceder, 2013a; Hess et al., 2004; Iseki \& Taylor, 2009; Smith \& Wheat, 2012), as was the availability of information and high reliability levels, which, when related to transfers, create positive self-efficacy and perceived controllability, thus increasing PT user intention to use routes with transfers.

Finally, very few studies have addressed the issue of pure transfer penalty, and only Douglas and Jones (2013) estimated its value in minutes lost. According to Wardman and Hine (2000), the interchange itself is seen as a penalty, independent of the time spent waiting. Other research has identified the variables influencing the pure transfer penalty. Most point to the modes of transport involved in the transfer as being a significant factor for the pure transfer penalty (Currie, 2005; Iseki \& Taylor, 2009; Liu et al., 1997; Navarrete \& Ortúzar, 2013; Palmer, James, \& Jones, 2011; Wardman, Hine, \& Stradling, 2001). According to these authors, metro-metro transfers are preferred to bus-bus transfers. One author indicates that unfamiliarity with a particular station or transfer, low frequencies and poor reliability penalize transfers regardless of waiting or walking time (Wardman, 2001); whereas others report a wide variability in the transfer penalty depending on the particular station where it occurs (Guo \& Wilson, 2004; Wardman et al., 2001). This highlights the importance of environmental factors such as shelter, lighting, information (static or realtime), comfort, safety and security, toilets, and others. Some authors (Douglas \& Jones, 2013; Raveau et al., 2014) have proved the significance of the pure penalty of a transfer taking place at the same or at different levels, and whether there are escalators or elevators.

In this comprehensive review, it is important to note that some factors affect more than one of the themes or subthemes identified. For instance, a transfer taking place at different levels affects the actual walking time, since people walk more slowly on stairs; the perception of walking time, as there is a penalty associated with this extra effort required; and, finally, the pure transfer penalty, as it psychologically dissuades the user from making a transfer. Only a few authors consider the pure transfer penalty in isolation from walking and waiting time (Douglas \& Jones, 2013; Wardman \& Hine, 2000). There is, therefore, a need to investigate the factors affecting the transfer penalty, and especially those affecting the pure transfer penalty.

\subsection{Approaches to identifying the factors in the literature}

Most of the studies reviewed focus on quantifying rather than identifying the factors, although many reach conclusions as to which of the study factors are most significant. The literature reveals two main approaches to identifying the most important factors determining the transfer penalty. The most commonly used consists of conducting stated preference (SP) surveys among public transport users in several interchange facilities (Ceder et al., 2013; Chowdhury \& Ceder, 2013a, 2013b, 2013c; Chowdhury et al., 2014; Douglas \& Jones, 2013; Liu et al., 1997; Navarrete \& Ortúzar, 2013; Schakenbos, 2014). Data obtained from these surveys, which may include some revealed preference (RP) questions on sociodemographic or trip characteristics (Chowdhury \& Ceder, 2013a, 2013c; Chowdhury et al., 2014; Liu et al., 1997; Navarrete \& Ortúzar, 2013; Schakenbos, 2014), were analyzed using different statistical models, usually following a logit specification, to determine the most significant variables.

The second approach involved a review of the data and conclusions from previous studies on the topic to obtain new results. This is the case of Iseki and Taylor (2009), who made an extensive review of the literature on assessments of waiting time, walking time, transfer time, and transfer penalties relative to in-vehicle time; and Wardman and Hine (2000), who conducted a meta-analysis of previous studies on the issue. The second methodology has the advantage of providing a more detailed analysis than the isolated studies on which they are based, by exploiting their evidence as a whole (Abrantes \& Wardman, 2011), although any bias in the original studies cannot be controlled (Shires \& de Jong, 2009).

Qualitative research methods are playing an increasing role, and are widely recognized as consolidated research approaches in the social sciences (Denzin \& Lincoln, 2011). These mainly involve conducting in-depth interviews and focus groups, both of which are qualitative research techniques that have been in use for almost 50 years (Kitzinger, 1995; Krueger \& Casey, 2015; Morgan, 1996). From their initial application in the field of social sciences, qualitative approaches such as focus groups are increasingly being used in transportation-related studies to conduct in-depth analyses of complex phenomena, including thoughts, attitudes, feelings, and emotions inherent to transport-related behaviors that are difficult to capture with quantitative methods such as formal questionnaires (Clifton \& Handy, 2003; Hine \& Scott, 2000). Qualitative techniques can be used in 
combination with quantitative approaches to fill the gaps left by quantitative techniques (Clifton \& Handy, 2003).

Qualitative methods can gather information directly from transport users in order to understand why user decisions are being made. There are important recent contributions on the use of FG in the field of transport (Carreira et al., 2013; Emmerson, Guo, Blythe, Namdeo, \& Edwards, 2013; Ferrer et al., 2015, 2018; Fishman, Washington, \& Haworth, 2012; Gwyther \& Holland, 2014a; Hine \& Scott, 2000; Hopkins \& Mandic, 2017; Huth et al., 2014; Ibeas, Dell'Olio, \& Montequín, 2011; Kenyon \& Lyons, 2003; Simons et al., 2014).

To our knowledge no research has yet been done in the particular case of transfers using qualitative methods to specifically identify the factors affecting the transfer penalty, with the exception of the work by Navarrete (2010), who uses FG to identify relevant variables for a SP survey on transfer penalties in Santiago de Chile. Our approach goes further, and contributes to the study of transfer penalties through qualitative research in two cities and with diverse age groups, and analyses comprehensive information on how transfers are perceived in different locations and by different population groups.

\section{Method}

The data were collected and analyzed by a multidisciplinary research team consisting of transport engineers and one psychologist.

\subsection{Case studies to conduct the research: Vitoria-Gasteiz and Madrid}

In this research, the two Spanish cities of Vitoria-Gasteiz and Madrid (Figure 1 shows their location) were selected as case studies, since it is widely acknowledged that transport penalties vary between cities (Iseki \& Taylor, 2009). Prior to conducting the focus groups, the researchers visited major transport facilities and held meetings with key policy makers and stakeholders in both cities. This helped us gain an overall view of the topology and transport system in each city. Finally, key data on the transport system and mobility in these cities was collected from several sources, including the Spanish Metropolitan Mobility Observatory (Monzon, Cascajo, Diaz, \& Barberan, 2016) and recent mobility surveys in both cities (Transport Research Centre UPM TRANSyT, 2015). A brief summary of the key information is included below.

Vitoria-Gasteiz is a medium-sized city with 242,000 inhabitants (Instituto Nacional de Estadística, 2017), and is the capital of the Basque Country in northern Spain. Its transport system consists of a bus network with 10 lines and a tram network with two lines. All tram stations provide real-time information through panels. An important characteristic of this city is its compactness, producing a modal share in which only $24 \%$ of journeys are made by car, $53.5 \%$ on foot, $13.4 \%$ by bike, and $7.9 \%$ by public transport, with $0.45 \%$ intermodal trips (Transport Research Centre

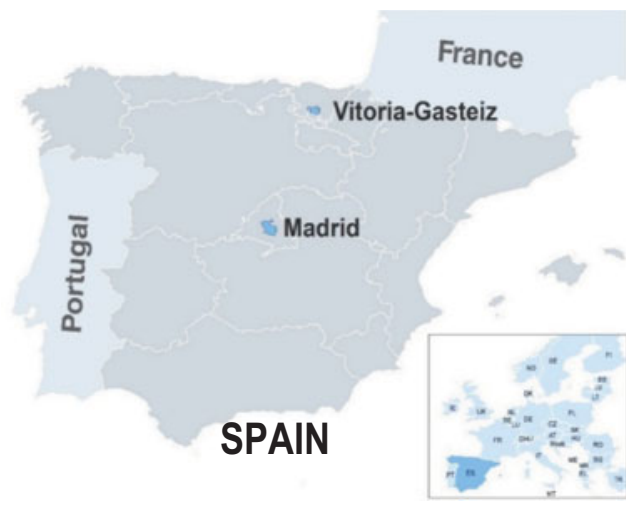

Figure 1. Location of Vitoria-Gasteiz and Madrid.

UPM - TRANSyT, 2015). 75\% of the journeys take less than $20 \mathrm{~min}$. Vitoria-Gasteiz has cold winters with frequent rain, sometimes turning into snow.

Madrid is the capital of Spain and the largest city in the country, with more than 3 million inhabitants and over 6 million in its metropolitan area (Instituto Nacional de Estadística, 2017). 12.9 million trips are made daily in the Madrid metropolitan area, with an average trip of $6 \mathrm{~km}$ and $29 \mathrm{~min}$. Its transport network consists of 313 urban bus lines, 328 interurban bus lines, 12 metro lines, 4 light metro lines, and 9 metropolitan railway lines. This dense transport network produces a balanced modal share: $40.4 \%$ trips are made by car, $28.4 \%$ by public transport, $29.9 \%$ on foot, and $0.5 \%$ by bike; $9 \%$ of PT trips are intermodal (Monzon et al., 2016). About 50\% of bus stops and all metro stations provide real time information through panels. There is also a range of apps to inform users about waiting times while on route. The climate in Madrid is cold in winter and hot in summer, with rain concentrated in spring and autumn, and rare in summer.

We chose to conduct this research in Vitoria-Gasteiz because it has recently restructured its public transport network to offer a high-quality public transport service in a context where operational efficiency is becoming increasingly important. The restructured network entails more transfer points that previously, and it is very important to know how users perceive transfers in order to improve the quality of service and increase the use of public transport (Guo \& Wilson, 2004; Iseki \& Taylor, 2009).

Madrid was chosen for its dense and varied transport network, with multiple modes, different types of interchange points and the possibility of using different routes to make the same trip. People in Vitoria are not used to transfers, whereas in Madrid they are. The focus groups allow the comparison of the factors obtained in two cities of different sizes with different public transport networks and mobility patterns.

\subsection{Focus groups}

We conducted five focus groups, two in Vitoria-Gasteiz and three in Madrid. The recruitment procedure was separate for the two cities. It was decided to form different groups based on age, a common practice in FG (Kitzinger, 1995; Morgan, 1996), mainly because the passengers' age may imply functional declines that influence the perception of transfers, 
Table 2. Summary of statistics on focus groups participants.

\begin{tabular}{|c|c|c|c|c|c|c|}
\hline & & $\begin{array}{l}\text { Young adults } \\
\text { Madrid }\end{array}$ & \multicolumn{2}{|c|}{ Adults } & \multicolumn{2}{|c|}{ Elderly } \\
\hline Participants & & 8 & 7 & 6 & 5 & 4 \\
\hline Male & & $62.5 \%$ & $28.6 \%$ & $50.0 \%$ & $20.0 \%$ & $50.0 \%$ \\
\hline \multirow[t]{3}{*}{ Frequency of PT use } & Every day & $50.0 \%$ & $85.7 \%$ & $50.0 \%$ & $20.0 \%$ & $50.0 \%$ \\
\hline & Every week & $12.5 \%$ & $14.3 \%$ & $33.3 \%$ & $60.0 \%$ & $25.0 \%$ \\
\hline & Never & $0.0 \%$ & $0.0 \%$ & $0.0 \%$ & $0.0 \%$ & $0.0 \%$ \\
\hline \multirow[t]{4}{*}{ Trip motive } & Work & $33.3 \%$ & $100.0 \%$ & $66.7 \%$ & $0.0 \%$ & $0.0 \%$ \\
\hline & Study & $83.3 \%$ & $14.3 \%$ & $16.7 \%$ & $0.0 \%$ & $0.0 \%$ \\
\hline & Leisure & $66.7 \%$ & $85.7 \%$ & $83.3 \%$ & $100.0 \%$ & $50.0 \%$ \\
\hline & Other & $33.3 \%$ & $85.7 \%$ & $33.3 \%$ & $80.0 \%$ & $75.0 \%$ \\
\hline Make transfers & & $100.0 \%$ & $100.0 \%$ & $83.3 \%$ & $100.0 \%$ & $100.0 \%$ \\
\hline Type of transfer most used & Rail mode-rail mode & $100.0 \%$ & $100.0 \%$ & $0.0 \%$ & $80.0 \%$ & $0.0 \%$ \\
\hline
\end{tabular}

*Rail mode is metro in Madrid and light rail in Vitoria.

such as their perception of time (Emmerson et al., 2013; Gwyther \& Holland, 2014a; Hancock \& Rausch, 2010). Navarrete (2010) also applied this grouping by age.

\subsubsection{Participants}

We conducted two focus groups in Vitoria-Gasteiz: (1) a group of workers/students aged under 65, and (2) another group of retired people over 65. Participants were contacted via e-mail ${ }^{1}$ (sent to all the participants in the previous mobility survey in 2014) and by phone. The response rate was low, and the final composition was six people for the under-65s group and four people for the over-65s group.

We conducted three focus groups in Madrid: (1) a group of young adults aged under 30, (2) a group of adult workers composed of employed people under 65; and (3) a group of retired people aged over 65 . The first group was contacted by e-mail. ${ }^{2}$ From the resulting 16 responses, eight participants were chosen at the same time, ensuring gender equality. The second group was recruited from the employees of the Universidad Politécnica de Madrid-UPM and were contacted via e-mail. ${ }^{3}$ Eleven responses were received, and finally seven people attended the group. For the retired group, the e-mail recruitment procedure was replaced by notices in the surroundings of the facilities frequented by this age group. Five people were able to attend the meeting.

Thirty people thus took part in the five focus groups. A $€ 10$ incentive gift voucher for the participation was offered in all cases. Participants were also informed of the purpose and confidentiality of the data and statements made within the group. All the participants were asked for permission to make an audio recording of the conversations to prepare a transcript at the end of the focus group session.

We conducted the focus groups from March to September 2015 in the two cities. Before starting the focus group, the participants completed a very short questionnaire

\footnotetext{
${ }^{1} 2,428$ e-mails were sent, and only 11 responses were received. The low response rate meant the survey participants had to be contacted randomly by phone, leading to the recruitment of four new participants.

${ }^{2} 3,146$ e-mails were sent through the College database.

${ }^{3} 4,873$ e-mails were sent.
}

on their socio-demographic data (age, gender, and occupation) and data about their PT trips: frequency of PT use -daily/weekly/occasionally/never; trip motive - work/study/ leisure/other; whether they make transfers - yes/no; and the most commonly-used of transfer type - bus-bus/rail-bus/ bus-rail/rail-rail. Table 2 shows a summary of statistics.

\subsubsection{Procedure}

All the focus groups were conducted in Spanish and lasted between 80 and $90 \mathrm{~min}$. We used a semi-structured template as an outline script (see Appendix) consistent with recommended focus group methodologies (Krueger \& Casey, 2015; Morgan, 1996; Tracy, 2010). The basic theoretical assumptions on the factors influencing transfer penalty were deduced from the literature review (Table 1).

In order to ensure the credibility of the results, triangulation procedures (Denzin \& Lincoln, 2011; Tracy, 2010) were carried out while running the focus groups. Two researchers acted as session facilitators while another two were present to take notes in case the recorder failed or the tape was inaudible. As detailed in the Appendix, the facilitators started the focus groups with an open question, leaving the group members to freely express their opinion on their transfer experience. The facilitators used a more "interventionist" approach when needed in specific cases, such as when contradictory opinions were given (Kitzinger, 1995; Krueger \& Casey, 2015). At the end of the focus groups, and by consensus among the facilitators, if any of the factors listed in Table 1 is not spontaneously mentioned by the participants, the facilitators raised them in order to gather the relevant information.

\subsection{Data analysis}

We carried out a thematic analysis (Attride-Stirling, 2001) following a theoretical approach (Braun \& Clarke, 2006) to find repeated patterns of meaning (themes) across the subject's descriptions. After the audio recordings were transcribed, the first stage consisted of a coding procedure following the general guidelines for qualitative research (Denzin \& Lincoln, 2011; Strauss \& Corbin, 1998; Tracy, 
Table 3. Summary of factors affecting the perception of transfers found in the focus groups.

\begin{tabular}{|c|c|c|}
\hline Theme & Factors & Studies referencing the factors \\
\hline \multirow[t]{2}{*}{ Personal characteristics } & Health status & Iseki \& Taylor 2009 \\
\hline & Familiarity with the route/network & Iseki \& Taylor 2009 \\
\hline \multirow[t]{5}{*}{ Trip characteristics } & Trip purpose & Schakenbos 2014 \\
\hline & Carrying bags/luggage & Wardman \& Hine 2000 \\
\hline & Time of day & Raveau et al. 2014 \\
\hline & Being late & Iseki \& Taylor 2009 \\
\hline & Availability of real-time information & Chowdhury \& Ceder 2013c; Dziekan 2008 \\
\hline \multirow{4}{*}{ Time } & Waiting time in transfer & Navarrete \& Ortúzar 2013 \\
\hline & Walking time in transfer & Navarrete \& Ortúzar 2013 \\
\hline & Transfer time (walking + waiting) & $\begin{array}{l}\text { Schakenbos et al. 2016; Schakenbos 2014; } \\
\quad \text { Chowdhury \& Ceder 2013a; Douglas \& Jones } 2013\end{array}$ \\
\hline & Transfer time to total travel time & NEW \\
\hline \multirow[t]{5}{*}{ Built environment } & Comfort in transfer & Raveau et al. 2014; Ceder et al. 2013a \\
\hline & Safety and security & Chowdhury \& Ceder 2013c \\
\hline & Interchange facility & Navarrete \& Ortúzar 2013; Wardman \& Hine 2000 \\
\hline & Crowding & $\begin{array}{l}\text { Raveau et al. 2014; Guo \& Wilson 2011; } \\
\text { Wardman \& Hine } 2000\end{array}$ \\
\hline & Climate & Iseki \& Taylor 2009 \\
\hline \multirow[t]{6}{*}{ Transfer characteristics } & Same/different level transfer & $\begin{array}{l}\text { Raveau et al. 2014; Douglas \& Jones 2013; } \\
\quad \text { Guo \& Wilson 2011; Wardman \& Hine } 2000\end{array}$ \\
\hline & Escalators/elevators & $\begin{array}{l}\text { Schakenbos et al. 2016; Raveau et al. 2014; Navarrete } \\
\quad \text { \& Ortúzar } 2013\end{array}$ \\
\hline & Walking distance in transfer & Schakenbos et al. 2016; Guo \& Wilson 2011 \\
\hline & Transfers between different modes & $\begin{array}{l}\text { Schakenbos et al. 2016; Schakenbos 2014; } \\
\text { Douglas \& Jones 2013; Currie 2005; Liu et al. 1997; } \\
\text { Wardman \& Hine 2000 }\end{array}$ \\
\hline & Frequency of connecting services & $\begin{array}{l}\text { Schakenbos et al. 2016; Schakenbos 2014; Iseki \& } \\
\text { Taylor 2009; Wardman \& Hine 2000; Liu } \\
\text { et al. } 1997\end{array}$ \\
\hline & Reliability & Ceder et al. 2013a; Chowdhury \& Ceder 2013b \\
\hline \multirow[t]{2}{*}{ Pure penalty } & Mental effort & NEW \\
\hline & Activity disruption on-board & NEW \\
\hline
\end{tabular}

2010). The coding procedure was done manually, and was initially driven by the list of potential factors identified in the literature (Table 1). Where new categories were found, they were added later by agreement among the researchers.

As suggested by Sandelowski (2001), and previously used by Van Cauwenberg et al. (2012) and Simons et al. (2013, 2014), the qualitative data were reinforced by quantitative counts of the number of participants discussing certain factors influencing their choice of transportation. Thus, when a factor was discussed by less than $25 \%$, we called it "few", for between $25 \%$ and $50 \%$, we called it "some", when discussed by $50 \%$, we called it "half", for between $50 \%$ and $75 \%$, we called it "many" and for more than $75 \%$ of the participants, we called it "almost all".

\section{Results and discussion}

Qualitative data analysis revealed six main themes with several factors affecting user perception of transfer penalty: personal characteristics; trip characteristics; time-related factors; built environment factors; transfer characteristics; and pure penalty factors. Table 3 gives a summary of the main factors emerging in the different focus groups, and whether a given factor was already found in the literature review or was new.

The following sections include the results of the factors debated by at least some participants (25-50\%) in the focus groups. Statements made by participants during the focus groups, which are identified by gender, age and city, support the findings.

\subsection{Personal characteristics}

The factors mentioned by the focus group participants on this theme were familiarity with the route/PT network, health status, trip purpose, bags/luggage, being late, and time of the day. The most discussed in the FG were familiarity with the route or with the PT network and the health status of the individual.

\subsubsection{Familiarity with the route or the PT network}

The factor "familiarity of the user with the route or the PT network" was mentioned by a similar number of people in both cities, less than half in Madrid and slightly more than half in Vitoria. However, significant differences were seen among age groups: this factor was mentioned by only some students, but by almost all the elderly, and is related to the frequency of use of the transit systems. As stated by Woyciechowicz and Shliselberg (2005), regular transit system users, with a high familiarity with the route or the entire transit system, have relatively lower weights for waiting and walking than those who are unfamiliar with it. Likewise, familiarity with the system improves spatial orientation and wayfinding, and also enhances the positive feelings towards the use of the PT system (Dziekan, 2007), and hence the use of routes with transfers.

The "transfer experience" includes walking and waiting times which have affective dimensions (Friman, 2010; Jensen, 2012). Unfamiliarity with the trip may increase the perception of uncertainty related with the transfer and thus deter people from choosing this option. 
In Madrid, we found one participant in the elderly group who took the same routes because she knew where the elevators were located.

I like travelling with her when I go to Sol [metro station in the city center], because she knows where all the elevators are in the transfer we have to make [woman, 74 years old, Madrid].

One student in Madrid stated the importance of familiarity with the network for choosing routes with transfers.

I know the public transport network well so I can be adventurous with transfers or make changes in my route; it is important to have the map in your head (male, 21 years old, Madrid)

\subsubsection{Health status}

The health status of individuals was mentioned by almost half the participants in Madrid and by some participants in Vitoria. It was more important in the elderly group than in the others, and discussed by many participants in the over 65 groups. This factor is closely related to the age of the individual, and is essential in determining both actual and perceived walking distance and time (Iseki \& Taylor, 2009). Most of the over 65s group in the Madrid FG claimed to have mobility problems and said they preferred to walk than to make an inconvenient transfer:

I'm not as agile as I was, and I find stairs and escalators very difficult; they sometimes make me nervous because they're very steep [woman, 82 years old, Madrid].

You don't see too many elderly people on the metro because we don't like stairs and escalators, and long corridors. We prefer to walk than to make awkward transfers [woman, 69 years old, Madrid].

This factor is not as important in Vitoria as in Madrid, because transfers are at the same level, so passengers with reduced mobility (the elderly, people on crutches, pregnant women and others) have less difficulty in making the transfer. The poorer the health status of an elderly person, the greater the perception of the distance during the transfer, and even more so when stairs or escalators are involved.

\subsection{Trip characteristics}

The main factor relating to trip characteristics, and one that emerged in all the focus groups, is "availability of real-time information". Other factors mentioned by half the participants only in the young adults group were trip purpose, time of the day and being late, all of which are closely related, and which this group rated as having equal importance to time-related factors.

\subsubsection{Real-time information}

Mobile apps and real-time information came second in the groups. All participants were very satisfied with the availability of real-time information; however, while young people preferred to consult real-time information via mobile apps (they even decide which station to make the transfer at by checking the actual waiting time of connecting services on their mobile phones while on route), older participants favor real-time information provided on panels at transit stops:

One good thing [about transfers] is that some stops show the real waiting time for the next bus. But not all of them [woman, 79 years old, Vitoria].

Many recent studies have considered the benefits of realtime passenger information (Daskalakis \& Stathopoulos, 2008; Lappin, 2000; Monzon, Hernandez, \& Cascajo, 2013; Tang \& Thakuriah, 2012). They concluded that it contributes to more efficient travel by enabling better use of waiting time and producing positive psychological effects such as reduced anxiety, increased feeling of personal safety, a general sense of trust in the PT system, increased ease of use, better overall image of the system, and greater passenger satisfaction. Although not all the literature focuses on the transfer experience, some of the findings appeared in the focus groups.

I use a mobile phone app a lot. I consider those minutes as saved time. I think they're really useful [woman, 21 years old, Madrid].

When you know the waiting time for the next train or bus, waiting becomes more enjoyable and relaxing [woman, 27 years old, Madrid].

\subsection{Time factors}

The main factor arising in all the focus groups is "time", in its different components; walking time, waiting time, transfer time, and total travel time:

The worst thing about transfers is the time [woman, 46 years old, Vitoria].

"Time" was mentioned by almost all participants. In the younger group, waiting time is the most important factor affecting transfer penalties, and is perceived as a waste of time. They also mention transfer time as a proportion of total travel time:

A 5-minute transfer in a 15-minute trip is not the same as a 10minute transfer in a 60-minute trip [woman, 25 years old, Madrid].

This ratio of transfer time to total travel time was not found in the literature reviewed, so this is a new factor arising from this research.

"Time" was slightly more important in Vitoria than in Madrid, probably due to the shorter travel times in a smaller city. It is sometimes not worth transferring because the waiting time is longer than the time needed to cover the second stage of the trip on foot.

I can transfer at three or four stops. If I'm at the stop and see [on the real time information panels], I have to wait five minutes for the next bus, then I make the transfer, but if I see I have to wait ten minutes I don't, because it only takes me ten minutes to get home on foot [man, 26 years old, Vitoria].

This is consistent with the literature consulted (Iseki \& Taylor, 2009; Wardman \& Hine, 2000). The value of the time also appeared to be less important among the elderly than the young. 


\subsection{Built environment factors}

The factors in this category mentioned by the focus group participants were crowding, comfort, security, interchange facility, and climate. Among them, the most discussed in the FG were crowding and climate.

\subsubsection{Crowding}

The crowding factor was more important in Madrid than in Vitoria, and was mentioned by many participants in Madrid. This may be because Madrid has several overcrowded metro stations and interchanges, and the time taken to access the escalators doubles when there are too many people. In line with Wardman and Hine (2000) and Raveau et al. (2014), passengers were concerned with overcrowding at busy interchanges and busy platforms.

The problem I see is that at certain times everyone's going home after work and I have to walk against the crowd [man, 22 years old, Madrid].

\subsubsection{Climate}

Climate was also identified by Iseki and Taylor (2009) as one of the factors influencing the perception of transfer penalties. In our study, this factor was more relevant in Vitoria, and was mentioned by some of the respondents. This is due to the city's cold and rainy climate, which means people prefer to wait in a transit stop for the next bus/tram than to walk through rain or snow. In other words, in unpleasant environments such as rainy or snowy weather, the penalty associated to walking time increases, and more people consider the possibility of making a transfer. All young adults who participated in the focus groups in Vitoria declared they transfer more in bad weather.

I don't like transfers because you waste a lot of time waiting for the next train or bus. I only make transfers in bad weather (rain or snow) [woman, 32 years old, Vitoria].

\subsection{Transfer characteristics}

The factors in this category mentioned by the focus group participants were different levels in transfers, presence of escalators/elevators, walking distance during transfer, transfers between different modes, coordination between services, frequency and reliability, almost all of which were discussed in the FG. The existence of escalators/elevators is closely related to the factor "different levels in transfer", so they are explained together.

\subsubsection{Different levels in transfer}

Participants in the Madrid focus groups only mentioned this, as transfers in Vitoria do not involve different levels, while Madrid has metro-bus or metro-metro transfers on different levels. Almost all participants admitted that they avoid some metro transfers because they are too deep (requiring passengers to go up/down more than three levels of escalator), even if they have no mobility problems.
This factor also appeared in the literature. According to Raveau et al. (2014), if a change in levels has to be made, users prefer to descend rather than ascend, as ascending seems to be mentally associated with greater effort. The presence of an escalator, a longer ramp, and a same-level transfer improve the transfer experience (Guo \& Wilson, 2011). Therefore, in addition to the physical effort required for transfers between different levels, the focus groups revealed a new factor relating to mental effort, a psychological penalty for the depth of the platforms.

I usually avoid Cuatro Caminos, Guzmán el Bueno and Metropolitano [metro stations], because the stairs are so awful. Yes, there are escalators, but the perception is horrible because the platforms are so deep [man, 21 years old, Madrid].

\subsubsection{Walking distance during transfer}

Half the participants in both Madrid and Vitoria mentioned the walking distance. However, this factor appears to be perceived differently by different age groups. While some students only mentioned it, nearly half the participants in the 18-65 group cited it, and it was particularly important among the elderly, almost all of whom mentioned it. The health status of the traveller is significant in determining both actual and perceived walking distance and time (Iseki \& Taylor, 2009). The poorer the health status of the elderly, the longer the transfer distance appears. Particularly in the case of Madrid, elderly participants said the transfer distances are generally very long, and that they find it very challenging when the escalators are out of order in metro-metro transfers.

\begin{abstract}
Many elderly people don't like making transfers in the metro network because they're afraid of the stairs; they're inconvenient and sometimes dangerous [woman, 69 years old, Madrid].
\end{abstract}

\subsubsection{Transfers between different modes}

Another factor highlighted in the literature and which arose in the groups concerns transfers between different modes. This was mentioned by half the participants, and was more important in Madrid than in Vitoria, where only some participants cited it, probably because of the greater availability of transport modes in Madrid. Many participants in the elderly group in Madrid confessed to avoiding metro-metro transfers because they do not like escalators and prefer to make transfers at surface level. This is similar to the finding of Douglas and Jones (2013), where the penalty for a same-mode transfer, e.g. metro-metro or bus-bus tended to be smaller than a transfer involving a change of mode, especially a metro-bus transfer when there are no directions to the bus stop.

Bus stops are usually some distance from the metro station entrances; metro-bus transfers are not an option because the networks aren't coordinated, so the total transfer time is very high [man, 32 years old, Madrid].

The bus stops are sometimes poorly signposted so you can't see them when you come out of the metro. So metro-bus is the worst transfer [woman, 53 years old, Madrid]. 


\subsubsection{Coordination}

Coordination between services can be achieved by synchronizing the schedules of the different services. This is easier within the same transport mode, but becomes more complicated when schedules of different transport modes need to be synchronized. A lack of coordination can sometimes mean missed connections and delays, which have been found to cause anxiety to the users (Cheng, 2010). The coordination between modes and services was found to be a more relevant factor in Vitoria than in Madrid, as it was mentioned by most of the participants in Vitoria. Many of them complained about a lack of coordination, mainly in bus services:

It would be nice if bus drivers would wait when they see another bus approaching the stop so the passengers can transfer [man, 71 years old, Vitoria].

\subsubsection{Frequency and reliability}

Frequency of service and reliability were also found to be relevant factors for transfers, as expected from the literature review (Ceder et al., 2013; Iseki \& Taylor, 2009; Schakenbos, 2014; Wardman \& Hine, 2000). These factors are more important in Vitoria (mentioned by many participants) than in Madrid (mentioned by half the participants). This may be because frequencies and distances in Vitoria are lower, and people are thus more sensitive to this issue:

It's ten minutes. But because Vitoria is a small city, ten minutes is enough time to walk to my destination instead of waiting for the next bus [man, 26 years old, Vitoria].

\subsection{Pure penalty}

Finally, two factors were found that did not appear in the literature, and which are related to the pure transfer penalty. These factors were mental effort and activity disruption.

\subsubsection{Mental effort}

Mental effort emerged in all the focus groups except the over 65s. Some of the participants in the students group mentioned it. This factor refers to the extra mental effort demanded of passengers when making a transfer and needing to remain alert throughout the whole journey in order not to miss their transfer stop.

I'd rather sit on the bus than have to be thinking 'two stops until I have to get off. If I fall asleep I'll miss my stop' [woman, 25 years old, Madrid].

This factor did not arise in the elderly groups. One possible explanation is that some barriers to the transfer experience may be perceived more strongly by older users (Broome et al., 2013; Emmerson et al., 2013; Hancock \& Rausch, 2010), raising the need for "age-friendly mobility" (Murray, 2015). However, this possibility should be validated in future research.

\subsubsection{Activity disruption}

The second factor concerns the utility of in-vehicle time, especially on longer trips when the time on-board can be used for activities such as reading, listening to music, or even sleeping. This was only raised in the focus groups in Madrid, especially among the younger participants, half of whom mentioned it. This may be due to the longer travel distances in Madrid, where average travel times are higher than in Vitoria. Transfers were therefore seen as a disruption to the on-board activity associated with the fact of transferring:

I prefer a longer trip without any transfers so I can read or study, to a shorter trip with transfers because it interrupts whatever activity you're doing. What's more, when I'm revising for exams I take the longest route with the fewest possible transfers, even though it takes longer [man, 21 years old, Madrid].

Participants admitted that when they are engaged in an activity like reading or studying during the trip, any transfer interrupts this activity, even if the transfer is ideal (no walking and without waiting time). The activity disruption is somehow related to mental effort: you must be aware of the stop where you have to get off; thus, preventing you from fully concentrating on your on-board activity, which must also be interrupted when you get off to make the transfer.

\section{Conclusions}

The aim of this article was to identify the most relevant factors affecting user perception of the transfer penalty in multimodal urban trips in order to enable policy makers to concentrate their efforts and improve the travel experience of public transport users.

We started by carrying out a literature review of the most important research on route choice, travel penalization, and the transfer penalty, from which a total of 45 factors were identified (Table 1). The literature review was supplemented by a qualitative study conducted in two different-sized Spanish cities consisting of various focus groups stratified by age, in order to determine user feelings and intentions towards transfers and identify differences among cities and age groups.

The results indicate that the perception of transfers is influenced by a combination of factors. Differences were also found between cities. Common factors between cities are both walking and waiting time during transfers, real-time information, mental effort, familiarity with the route, trip purpose, and climate. However, in Madrid factors like crowding, different levels between transfers, and activity disruption were important for the focus group participants. One of the main conclusions of the Vitoria FG was that since travel distances are very short, the decision of whether or not to transfer does not compete with the direct route (without transfer), but with making the last leg of the trip on foot. This is why factors like the absence of coordination between services is the main reason transfers are penalized.

We found differences not only between cities but also between age groups. For groups under 65, time was found to be the most important factor, followed by real-time information and crowding. Two new factors not previously seen in the literature were identified within these groups: mental 
effort and activity disruption. These are genuinely pure penalties, as they are unrelated to walking or waiting during transfers. The first is associated to the extra mental effort required by passengers when making a transfer. They need to remain alert during the in-vehicle journey in order not to miss their transfer stop, and this causes some anxiety. Activity disruption concerns the use of in-vehicle time to engage in activities such as reading, listening to music, or sleeping. Older people seem to make less use of their onboard time for these kinds of activities. For the over 65 groups, the most important factors penalizing transfers are walking, unfamiliarity with the route, health status and lack of frequent services, most of which are related to their personal limitations, which make it difficult to walk quickly along long corridors, up and down stairs, or to get on and off buses.

Regarding the consistency of the above-mentioned results, they have been validated through quantitative approaches (stated preference - SP-surveys) in subsequent research works carried out by our research team (Cascajo, Garcia-Martinez, \& Monzon, 2017; Garcia-Martinez, Cascajo, Jara-Diaz, Chowdhury, \& Monzon, 2018). Resulting utility functions prove the importance of the attributes detected in the FG stage and confirm its findings. In summary, results from the SP models calibrated for Madrid show that those attributes most cited by FG participants were found statistically significant $(p<0.05)$. Selected relevant attributes causing disutility to commuters (measured in EIVM = equivalent in-vehicle minutes) are: crowding (3.6 increase in EIVM), transfer between different modes (2.2 increase), waiting time (1.1 increase), and walking time (0.8 increase). Additionally, the impact of the pure transfer penalty is perceived as an increase in 15.2-17.7 EIVM (for detailed information of the model calibration see Garcia-Martinez et al., 2018).

There are several limitations to the present study. The main one concerns the limited representation of participants in two out of three focus groups in Madrid. The student group and the under $65 \mathrm{~s}$ were recruited from the Universidad Politécnica de Madrid, located in a very specific location, not far from the city center. This may introduce some bias in the participants. However, although it may not be representative of the entire Madrid population, it was deemed to represent the transfer phenomenon. In fact, the main factors emerging in both cities were similar and consistent with the literature. Regarding the size of each FG, there is no consensus on the literature on an ideal number of participants, although it is agreed that smaller focus groups show greater potential. Most cited guidelines suggest the use of group sizes between 5 and 8 participants, although smaller focus groups, with 4 to 6 participants, are becoming increasingly popular (Krueger \& Casey, 2015). The authors' opinion is in line with this argument, as their experience shows small groups can be moderated more easily, although fewer opinions are generated. Lastly, the study is restricted to urban transfers made within the city, so the results may not be extrapolated to all transfer types, as interurban transfers have different characteristics. In the future research, it would be interesting to extend this methodology and conduct focus groups with a wider set of participants, including participants from different population profiles and other transfer types.

The findings provide some insights for different stakeholders to improve PT systems. Both the literature and the focus groups indicate that the most effective measure for diminishing the perception of the transfer penalty is to reduce the time users spend walking and waiting in transfers. In our opinion, increasing frequencies by operators would decrease waiting time, while enhancing waiting conditions (shelter, seats, temperature, lighting, safety and security and so on) would help improve user perception. New station designs should aim to shorten distances as much as possible, and consider mechanical walkways to reduce walking times. These actions are suggested for design planners.

Public transport authorities and operators should concentrate their efforts on providing real-time information to passengers, either via panels at stops and on platforms or via mobile apps; according to the results of the FG the preference is for in situ information, as this was found to be very relevant to all age groups, while mobile apps were only so to younger participants. According to our experience, city characteristics such as size, mobility patterns and the layout of the public transport network should not be overlooked when seeking to improve user perception of transfers in multimodal urban trips. Public transport operators would do well to improve the frequency and reliability of the service in small cities such as Vitoria, with shorter distances and trip times on foot; and transport planners should design more extensive non-deep stations and improve signage in more populated cities such as Madrid, which involve complex public transport networks.

Finally, there is a need to reduce the transfer penalty caused by users' apparent mental effort in response to the disruption of any possible in-vehicle activity. From the authors' point of view, this penalty can be reduced to the minimum by designing real transfer areas with continuity between transport modes to make the transfer experience seamless, in addition to continuity in information and communication to improve user intention to use routes with transfers.

\section{Funding}

The authors thank the Spanish Ministry of Economy and Competitiveness and its State Programme for Research, Development and Innovation oriented to Challenges in Society (project TRA2013-45239-R) for providing the necessary funding; the Environmental Studies Centre (CEA) in Vitoria-Gasteiz and the Rectorate of the Madrid Polytechnic Universidad (UPM) for their help in recruiting the focus groups.

\section{ORCID}

Rocio Cascajo (D) http://orcid.org/0000-0002-9962-4475

\section{References}

Abrantes, P. A., \& Wardman, M. R. (2011). Meta-analysis of UK values of travel time: An update. Transportation Research Part A: Policy and Practice, 45, 1-17. 
Atkins, W. S., \& Polak, J. (1997). Bus reliability - Stated preference research. London: For the Department of Transport.

Attride-Stirling, J. (2001). Thematic networks: An analytic tool for qualitative research. Qualitative Research, 1, 385-405.

Braun, V., \& Clarke, V. (2006). Using thematic analysis in psychology. Qualitative Research in Psychology, 3, 77-101.

Bronzaft, A. L., Dobrow, S. B., \& O’Hanlon, T. J. (1976). Spatial orientation in a subway system. Environment and Behavior, 8, 575-594.

Broome, K., Worrall, L., Fleming, J., \& Boldy, D. (2013). Evaluation of age-friendly guidelines for public buses. Transportation Research Part A: Policy and Practice, 53, 68-80.

Bruun, E. C. (2013). Simple and Complex Mathematical Models. In Better public transit systems: analyzing investments and performance (pp. 173-219). Abingdon, UK: Routledge.

Carreira, R., Patricio, L., Jorge, R. N., \& Magee, C. (2014). Understanding the travel experience and its impact on attitudes, emotions and loyalty towards the transportation provider? A quantitative study with mid-distance bus trips. Transport Policy, 31, 35-46.

Carreira, R., Patricio, L., Jorge, R. N., Magee, C., \& Van Eikema Hommes, Q. (2013). Towards a holistic approach to the travel experience: A qualitative study of bus transportation. Transport Policy, 25, 233-243.

Cascajo, R., Garcia-Martinez, A., \& Monzon, A. (2017). Stated preference survey for estimating passenger transfer penalties: design and application to Madrid. European Transport Research Review, 9, 1-11.

Ceder, A., Chowdhury, S., Taghipouran, N., \& Olsen, J. (2013). Modelling public-transport users' behaviour at connection point. Transport Policy, 27, 112-122.

Ceder, A., Hadas, Y., McIvor, M., \& Ang, A. (2013). Transfer Synchronization of Public Transport Networks. Transportation Research Record: Journal of the Transportation Research Board, 2350, 9-16.

Cheng, Y. H. (2010). Exploring passenger anxiety associated with train travel. Transportation, 37, 875-896.

Chowdhury, S., \& Ceder, A. (2013a). A psychological investigation on public-transport users' intention to use routes with transfers. International Journal of Transportation, 1, 1-20.

Chowdhury, S., \& Ceder, A. (2013b). Definition of planned and unplanned transfer of public transport service and user decisions to use routes with transfers. Journal of Public Transportation, 16, $1-20$.

Chowdhury, S., \& Ceder, A. (2013c). The effect of interchange attributes on public-transport users' intention to use routes involving transfers. Psychology and Behavioral Sciences, 2, 5.

Chowdhury, S., Ceder, A., \& Sachdeva, R. (2014). The effects of planned and unplanned transfers on public transport users' perception of transfer routes. Transportation Planning and Technology, 37, 154-168.

Clifton, K. J., \& Handy, S. L. (2003). Qualitative Methods in Travel Behaviour Research. In Transport Survey Quality and Innovation (pp. 283-302). Emerald Group Publishing Limited.

Currie, G. (2005). The demand performance of bus rapid transit. Journal of Public Transportation, 8, 41-55.

Daskalakis, N., \& Stathopoulos, A. (2008). Users' perceptive evaluation of bus arrival time deviations in stochastic networks. Journal of Public Transportation, 11, 25-38.

De Keizer, B., Kouwenhoven, M., \& Hofker, F. (2015). New insights in resistance to interchange. Transportation Research Procedia, 8, $72-79$.

Denzin, N. K., \& Lincoln, Y. S. (2011). The SAGE handbook of qualitative research (3rd ed.). London: Sage.

Douglas, N., \& George, K. (2005). Estimating the passenger cost of station crowding. Paper presented at the 28th Australasian Transport Research Forum, Sidney, Australia.

Douglas, N., \& Jones, M. (2013). Estimating transfer penalties and standardised income values of time by stated preference survey. Australian Transport Research Forum, 1-21. Retrieved from http:// www.atrf.info/papers/2013/2013_douglas_jones.pdf

Dziekan, K. (2007). Learning an unfamiliar public transport system: An in-depth study from the user perspective in Stockholm. Royal Institute of Technology School of Architecture and the Built Environment.
Retrieved from http://citeseerx.ist.psu.edu/viewdoc/download?doi $=10.1 .1 .488 .8757 \& \mathrm{rep}=\mathrm{rep} 1 \&$ type $=\mathrm{pdf}$

Dziekan, K. (2008). Ease-of-use in public transportation: A user perspective on information and orientation aspects (Doctoral dissertation). KTH. Retrieved from http://www.diva-portal.org/smash/get/ diva2:13493/FULLTEXT01.pdf

Dziekan, K., \& Kottenhoff, K. (2007). Dynamic at-stop real-time information displays for public transport: effects on customers. Transportation Research Part A: Policy and Practice, 41, 489-501.

Dziekan, K., \& Vermeulen, A. (2006). Psychological effects of and design preferences for real-time information displays. Journal of Public Transportation, 9, 1-19.

Emmerson, C., Guo, W., Blythe, P., Namdeo, A., \& Edwards, S. (2013). Fork in the road: In-vehicle navigation systems and older drivers. Transportation Research Part F: Traffic Psychology and Behaviour, $21,173-180$.

Ferrer, S., \& Ruiz, T. (2018). The impact of the built environment on the decision to walk for short trips: Evidence from two Spanish cities. Transport Policy, 67, 111-120.

Ferrer, S., Ruiz, T., \& Mars, L. (2015). A qualitative study on the role of the built environment for short walking trips. Transportation Research Part F: Traffic Psychology and Behaviour, 33, 141-160.

Fishman, E., Washington, S., \& Haworth, N. (2012). Barriers and facilitators to public bicycle scheme use: A qualitative approach. Transportation Research Part F: Traffic Psychology and Behaviour, 15, 686-698.

Friman, M. (2010). Affective dimensions of the waiting experience. Transportation Research Part F: Traffic Psychology and Behaviour, 13, 197-205.

Garcia-Martinez, A., Cascajo, R., Jara-Diaz, S. R., Chowdhury, S., \& Monzon, A. (2018). Transfer penalties in multimodal public transport networks. Transportation Research Part A: Policy and Practice, 114, Part A, 52-66.

Guo, Z. (2003). Assessment of the transfer penalty for transit trips in downtown Boston. A GIS-based disaggregate modeling approach (Master Thesis). Massachusetts Institute of Technology.

Guo, Z., \& Wilson, N. (2004). Assessment of the transfer penalty for transit trips geographic information system-based disaggregate modeling approach. Transportation Research Record: Journal of the Transportation Research Board, 1872, 10-18.

Guo, Z., \& Wilson, N. (2007). Modeling effects of transit system transfers on travel behavior: Case of commuter rail and subway in downtown Boston, Massachusetts. Transportation Research Record: Journal of the Transportation Research Board, 2006, 11-20.

Guo, Z., \& Wilson, N. (2011). Assessing the cost of transfer inconvenience in public transport systems: A case study of the London Underground. Transportation Research Part A: Policy and Practice, $45,91-104$.

Gwyther, H., \& Holland, C. (2014). Feelings of vulnerability and effects on driving behaviour - A qualitative study. Transportation Research Part F: Traffic Psychology and Behaviour, 24, 50-59.

Hancock, P. A., \& Rausch, R. (2010). The effects of sex, age, and interval duration on the perception of time. Acta Psychologica, 133, $170-179$.

Hess, D. B., Brown, J., \& Shoup, D. (2004). Waiting for the bus. Journal of Public Transportation, 7, 67-84.

Hine, J., \& Scott, J. (2000). Seamless, accessible travel: Users' views of the public transport journey and interchange. Transport Policy, 7, 217-226.

Hopkins, D., \& Mandic, S. (2017). Perceptions of cycling among high school students and their parents. International Journal of Sustainable Transportation, 11, 342-356.

Horowitz, A. J., \& Thompson, N. A. (1995). Generic objectives for evaluation of intermodal passenger transfer facilities. Transportation Research Record, 1503, 104-110.

Horowitz, A. J., \& Zlosel, D. J. (1981). Transfer penalties: Another look at transit riders' reluctance to transfer. Transportation, 10, 279-282. 
Huth, V., Füssl, E., \& Risser, R. (2014). Motorcycle riders' perceptions, attitudes and strategies: Findings from a focus group study. Transportation Research Part F: Traffic Psychology and Behaviour, $25,74-85$.

Ibeas, A., Dell'Olio, L., \& Montequín, R. B. (2011). Citizen involvement in promoting sustainable mobility. Journal of Transport Geography, 19, 475-487.

Instituto Nacional de Estadística (INE), 2017. Spanish Statistical Office. http://www.ine.es/.

Iseki, H., \& Smart, M. J. (2012). How do people perceive service attributes at transit facilities? Transportation Research Record: Journal of the Transportation Research Board, 2274, 164.

Iseki, H., \& Taylor, B. D. (2009). Not all transfers are created equal: Towards a framework relating transfer connectivity to travel behaviour. Transport Reviews, 29, 777-800.

Jara-Díaz, S. R., Gschwender, A., \& Ortega, M. (2012). Is public transport based on transfers optimal? A theoretical investigation. Transportation Research Part B: Methodological, 46, 808-816.

Jensen, H. L. (2012). Emotions on the move: Mobile emotions among train commuters in the South East of Denmark. Emotion, Space and Society, 5, 201-206.

Kenyon, S., \& Lyons, G. (2003). The value of integrated multimodal traveller information and its potential contribution to modal change. Transportation Research Part F: Traffic Psychology and Behaviour, 6, $1-21$.

Kitzinger, J. (1995). Qualitative research. Introducing focus groups. British Medical Journal, 311, 299-302.

Krueger, R. A., \& Casey, M. A. (2015). Focus groups: A practical guide for applied research (5th ed.). Massachussets: Sage Publications.

Lacy, D., \& Bonsall, P. (2001). Misperception and mode choice. In World Conference on Transportation Research, Seoul, July 22-27, 2001.

Lappin, J. E. (2000). What have we learned about advanced traveler information systems and customer satisfaction? In What have we learned about intelligent transportation systems? (pp. 65-86). Washington, D.C.: U.S. Dept. of Transportation, Federal Highway Administration.

Liu, R., Pendyala, R., \& Polzin, S. (1997). Assessment of intermodal transfer penalties using stated preference data. Transportation Research Record, 1607, 74-80.

Monzon, A., Cascajo, R., Diaz, M. L., \& Barberan, A. (2016). Informe 2014 del Observatorio de la Movilidad Metropolitana. Madrid. Retrieved from http://www.observatoriomovilidad.es/images/stories/ 05_informes/informe_OMM2014.pdf

Monzon, A., Hernandez, S., \& Cascajo, R. (2013). Quality of bus services performance: Benefits of real time passenger information systems. Transport and Telecommunication, 14, 155-166.

Moreau, A. (1992). Public transport waiting times as experienced by customers. Public Transport International, 41, 52-71.

Morgan, D. L. (1996). Focus groups. Annual Review of Sociology, 22, 129-152.

Murray, L. (2015). Age-friendly mobilities: A transdisciplinary and intergenerational perspective. Journal of Transport \& Health, 2, 302-307.

Navarrete, F. J. (2010). Valoración Subjetiva del Transbordo en Transporte Público: Caso Santiago de Chile (MSc Thesis). Department of Transport Engineering and Logistics, Pontificia Universidad Católica de Chile (in Spanish).

Navarrete, F. J., \& Ortúzar, J. D D. (2013). Subjective valuation of the transit transfer experience: The case of Santiago de Chile. Transport Policy, 25, 138-147.

Palmer, D., James, C., \& Jones, M. (2011). Door to door journeys. Report produced by Transport Research Laboratory for Campaign for better Transport (June), $55 \mathrm{pp}$. Retrieved from, http://trid.trb. org/view.aspx?id =1149034

Raveau, S., Guo, Z., Muñoz, J. C., \& Wilson, N. (2014). A behavioural comparison of route choice on metro networks: Time, transfers, crowding, topology and socio-demographics. Transportation Research Part A: Policy and Practice, 66, 185-195.
Reynolds, M. M., \& Hixson, C. D. (1992). Transit vehicle meets system: A method for measuring transfer times between transit routes. Transportation Research Record, 1349, 35-41.

Sandelowski, M. (2001). Real qualitative researchers do not count: the use of numbers in qualitative research. Research in Nursing \& Health, 24, 230-240.

Schakenbos, R. (2014). Valuation of a transfer in a multimodal public transport trip: A stated preference research into the experienced disutility of a transfer between bus/tram/metro and train within the Netherlands (Master thesis). University of Twente. Retrieved from http://essay.utwente.nl/66111/1/SchakenbosR_0194689_openbaar.pdf

Schakenbos, R., La Paix, L., Nijenstein, S., \& Geurs, K. T. (2016). Valuation of a transfer in a multimodal public transport trip. Transport Policy, 46, 72-81.

Shires, J. D., \& de Jong, G. C. (2009). An international meta-analysis of values of travel time savings. Evaluation and Program Planning, 32, 315-325.

Simons, D., Clarys, P., De Bourdeaudhuij, I., De Geus, B., Vandelanotte, C., \& Deforche, B. (2013). Factors influencing mode of transport in older adolescents: A qualitative study. BMC Public Health, 13, 1.

Simons, D., Clarys, P., De Bourdeaudhuij, I., De Geus, B., Vandelanotte, C., \& Deforche, B. (2014). Why do young adults choose different transport modes? A focus group study. Transport Policy, 36, 151-159.

Smith, A. S., \& Wheat, P. (2012). Evaluating alternative policy responses to franchise failure: Evidence from the passenger rail sector in Britain. Journal of Transport Economics and Policy, 46, 25-49.

Strauss, A., \& Corbin, J. (1998). Basics of qualitative research: Procedures and techniques for developing grounded theory (2nd ed.). Thousand Oaks, CA: SAGE Publications Ltd.

Tang, L., \& Thakuriah, P. V. (2012). Ridership effects of real-time bus information system: A case study in the City of Chicago. Transportation Research Part C: Emerging Technologies, 22, 146-161.

Tirachini, A., Hensher, D. A., \& Rose, J. M. (2013). Crowding in public transport systems: Effects on users, operation and implications for the estimation of demand. Transportation Research Part A: Policy and Practice, 53, 36-52.

Tracy, S. J. (2010). Qualitative quality: Eight "big-tent" criteria for excellent qualitative research. Qualitative inquiry, 16(10), 837-851.

TRANSyT - Transport Research Centre UPM. (2015). 2014 VitoriaGasteiz Mobility Survey. Analysis of the results. Centro de Estudios Ambientales CEA. Ayuntamiento de Vitoria-Gasteiz.

Van Cauwenberg, J., Van Holle, J., Simons, V., Deridder, R., Clarys, P., Goubert, L., ... Deforche, B. (2012). Environmental factors influencing older adults' walking for transportation: a study using walkalong interviews. International Journal of Behavioral Nutrition and Physical Activity, 9, 85.

Wardman, M. (2001). A review of British evidence on time and service quality valuations. Transportation Research Part E: Logistics and Transportation Review, 37, 107-128.

Wardman, M., \& Hine, J. (2000). Costs of interchange: A review of the literature. Institute of Transport Studies, University of Leeds, Working Paper 546

Wardman, M., Hine, J., \& Stradling, S. (2001). Interchange and travel choice. Edinburgh: Scottish Executive Central Research Unit.

Woyciechowicz, A., \& Shliselberg, R. (2005). Wayfinding in public transportation. Transportation Research Record: Journal of the Transportation Research Board, 1903, 35-42.

\section{Appendix}

\section{Guide to follow in the focus groups}

Introduction $(5 \mathrm{~min})$

- The facilitators introduce themselves and the aim of the research project. 
- They explain the purpose of the focus group, how it works, and the incentive they will receive for participating.

Statement of Confidentiality and participant information (10 min)

- The facilitators deliver the Statement of Confidentiality (in Spanish) to be signed by participants:

The purpose of the focus group has been explained to all participants at the beginning. I agree to take part in the focus group and to provide my experiences and opinions concerning public transport, especially with regard to transfers. I am aware that the discussion group is audiorecorded with the sole purpose of making transcriptions. Nothing said within the group can be shared with anyone outside the project, unless any reference that can identify me is removed. All information provided by me, as well as the contributions made to the focus group will be kept in the strictest confidence and will not be shared with anyone outside the research project. I understand that my participation in this focus group is voluntary and that I can leave the group at any time.

The facilitators deliver a brief questionnaire on participant information to be answered at this time:

- Name and surname

- Age

- Gender

- Occupation

- Frequency of PT use

- Motives for using PT

- Do you make transfers?

- Specify the types of transfers you usually make
Open question $(10-15 \mathrm{~min})$

- The facilitators ask "What are the factors influencing your transfer experience?", leaving the group members to freely express their opinion on their transfer experience.

List of topics to cover (40-50 min), following Table 1:

1. Personal characteristics: age, gender, income, health status, familiarity with the route or with the PT network, when the user is running late.

2. Trip characteristics: frequency of the trip, user's regular mode, use of transfers, trip purpose, whether user carries bags/luggage, travelling alone/in group, time of the day.

3. Time: waiting time, activity/inactivity during waiting time, walking time in transfer, transfer time, in-vehicle time, saved time.

4. Environment: comfort, safety and security, existence of shelters, information, real-time information, interchange facility, crowding, climate.

5. Transfer characteristics: transfers at same/different level, existence of escalators/elevators, walking distance in transfer, transfers between different modes, frequency of connecting services, reliability, fare and ticketing system, more direct route, and total number of transfers in a trip.

6. Pure penalty.

Close of the focus groups

- When the focus group is complete, and all the topics have been covered, the facilitators thank all the participants and give out the $€ 10$ incentive gift voucher. 